\title{
Estimativa da valoração ambiental de um parque eólico no semiárido paraibano
}

Os parques eólicos no Brasil surgem como uma nova fonte de energia renovável e limpa, o que aumenta a matriz energética e diversifica os meios de produção de energia no país. A valoração ambiental é um método de mensuração de ativos ambientais, o qual se baseia em avaliar as mudanças ocorridas nos bens naturais em todo o processo de implantação de um projeto ou empreendimento. Nesse sentido, o presente artigo tem como objetivo estimar a valoração ambiental de um parque eólico no Semiárido Paraibano. A mensuração foi feita pela metodologia da Valoração de uma Área Ambiental, devido à facilidade de compreensão e praticidade na aplicação. A partir dos resultados obtidos enfatiza-se que os valores médios de importância dos fatores ambientais variaram entre 2 e 3,5 e que o valor do passivo ambiental da área foi igual de - R\$ 483.719,55 (quatrocentos e oitenta e três mil e setecentos e dezenove reais e cinquenta e cinco centavos). A área apresenta valor ambiental negativo, devido os impactos ambientais negativos previstos na área.

Palavras-chave: Ativos Ambientais; Matriz Energética; Passivo Ambiental.

\section{Estimation of the environmental valuation of a wind farm in Paraiba semi-arid}

\begin{abstract}
The wind farms in Brazil plunge as a new source of renewable and clean energy, which increases energy and diversifies the means of energy production in the country. The environmental valuation arises as a method of measurement of environmental assets, which is based on assessing the changes occurring in the natural goodness in the whole process of implementation of a project or undertaking. In this sense, the present article aims to estimate the environmental valuation of a windfarm in the semi-arid region Brazil. The measurement was made by the methodology of Assessment of an Environmental Area, due to the ease of understanding and convenience in application. The results showed that the average values of importance of environmental factors varied between 2 and 3.5 and that the value of the environmental liabilities of the area was equal to - $R \$ 483.719 .55$. The area presents negative environmental value, because of the negative environmental impacts foreseen in the area.
\end{abstract}

Keywords: Environmental Assets; Environmental Liabilities; Energy Matrix.

Topic: Valoração e Economia Ambiental

Reviewed anonymously in the process of blind peer.
Received: $10 / 08 / 2018$

Approved: 24/09/2018
Lílian de Queiroz Firmino

Universidade Federal de Campina Grande, Brasil http://lattes.cnpq.br/6018151776912255 nailil 2008@hotmail.com

\section{Viviane Farias Silva (iD}

Universidade Federal de Campina Grande, Brasi http://lattes.cnpq.br/5011520274887172 http://orcid.org/0000-0002-5891-0328 flordeformosur@hotmail.com

\section{Andréa Karla Gouveia Cavalcanti}

Universidade Federal de Campina Grande, Brasil

http://lattes.cnpq.br/2784148914137982

andreakgcavalcanti@gmail.com
Gleyton Lopes Barboza Lacerda

Universidade Federal de Campina Grande, Brasil http://lattes.cnpq.br/0941837243510458 gleytonlb@gmail.com

\section{André Sobral (it)}

Universidade Federal de Campina Grande, Brasil http://lattes.cnpq.br/5934665934422750 http://orcid.org/0000-0002-7145-796X sobral.a@gmail.com

Dihego Souza Pessoa (iD

Universidade Federal de Campina Grande, Brasil

http://lattes.cnpq.br/8797044499355611

http://orcid.org/0000-0001-6954-4610

dihegopessoa@hotmail.com
Vera Lucia Antunes de Lima

Universidade Federal de Campina Grande, Brasil http://lattes.cnpq.br/5379077061489077 antunes.lima@gmail.com
Referencing this:

FIRMINO, L. Q.; SILVA, V. F.; CAVALCANTI, A. K. G.; LACERDA, G. L. B.; SOBRAL, A.; PESSOA, D. S.; LIMA, V. L. A.. Estimativa da valoração ambiental de um parque eólico no semiárido paraibano. Revista lbero Americana de Ciências Ambientais, v.9, n.7, p.333-344, 2018. DOI: http://doi.org/10.6008/CBPC2179-6858.2018.007.0031 


\section{INTRODUÇÃO}

A maior parte da energia produzida e consumida no Brasil provém de fontes renováveis, como a hidroeletricidade e a biomassa (BEZERRA et al., 2017). A energia hidroelétrica é considerada limpa, uma vez que não há queima de combustíveis fósseis para a sua geração com posterior liberação de resíduos que contribuem com a degradação do meio ambiente.

Dessa maneira observa-se que a fonte de energia elétrica brasileira é dependente de fatores climáticos, como a precipitação, sendo afetado em épocas de escassez hídrica, além de afetar diretamente as populações e o meio ambiente com os impactos ambientais. Nunes et al. (2010) relatam que a questão ambiental é um aspecto a ser levado em consideração, já que os períodos de estiagens influenciam as hidroelétricas e a produção de biomassa, onde as fontes renováveis surgem com o intuito de mitigar os efeitos provenientes de crises internacionais que atingem o mercado de combustíveis fósseis e/ou oscilação em hidroelétrica em épocas de restrição hídrica.

Para a implantação da Usina Hidroelétrica em Mauá no rio Tibagi, por exemplo, foi realizado um levantamento dos possíveis impactos sobre os Kaingang (população indígena), e entre as prováveis alterações constatou-se a possibilidade de conflitos sociais entre índios e não índios, a transmissão de doenças do homem branco para os índios, até questões econômicas e culturais (CRUZ et al., 2016). A produção de energia elétrica sacrifica diversos segmentos, sejam sociais, econômicos e ambientais, havendo modificações significativas que alteram a biodiversidade local, havendo a necessidade de geração de energia elétrica a partir de fontes alternativas que produzem impactos, gerando energia viável e limpa, que degrade o mínimo possível o ambiente e que promova a sustentabilidade do processo de desenvolvimento econômico, social e ambiental. Alguns autores como Alnasir et al. (2013) e Aquila (2015) discorrem que o caminho para autonomia energética é a eficácia na produtividade energética e otimização de inovações que gerem energia limpa e sustentáveis.

Na busca pela diversificação na produção de energia, os parques eólicos vêm sendo implantados nas últimas décadas como uma das formas de variar a matriz energética brasileira. Grande parte dos parques eólicos estão instalados na região semiárida nordestina, devido ao grande potencial eólico que alguns estados que compõem essa região possuem (TRALDI, 2014). Segundo Bezerra et al. (2017), esta região sobressai por sua excelente capacidade eólica, assim como vários locais com velocidades de vento com índices elevados do País, razão por ser âmbito de escolha para grandes investimentos neste setor. Estes autores ainda relatam que nos últimos anos a energia elétrica oriunda de fonte eólica tem aumentado significativamente, e um dos motivos foram os irregulares e baixos índices pluviométricos e a possibilidade de produzir energia com menores impactos.

No entanto, apesar da energia eólica estar sendo uma opção viável para a de geração de energia elétrica, com resultados satisfatórios, Aquila (2015) descreve algumas vantagens e desvantagens dessa tecnologia. Uma das vantagens, por exemplo, é a geração de energia em residências, tornando-se independente de concessionárias de energia. Por outro lado, uma das desvantagens é a produção de ruídos 
constante, área de implantação sem elevações, afastado das residências e seu custo elevado, mas que podem ser melhorados estes aspectos com o aprimoramento desta tecnologia. Azevedo et al. (2016) reconhecem que a energia eólica tem potencial para solucionar os problemas em relação a geração de energia do Brasil, com impactos socioeconômicos positivos, apesar de provavelmente ocasionar problemas ao meio ambiente relacionados às turbinas eólicas, contudo são questões que devem ser abordadas para que não haja efeito catastrófico.

Apesar de ser considerada uma energia limpa e renovável, a produção de energia elétrica a partir dos ventos provoca diversos impactos, como alteração da paisagem, no ciclo hidrológico, entre outros, onde os conflitos tornam-se visíveis, como a perturbação visual e descaracterização da paisagem, perda de habitat, alteração do uso do solo (privatização de antigas áreas comunais de plantio, pesca e criação de animais), aumento da vulnerabilidade dos ecossistemas naturais e das dinâmicas sociais, culturais e econômicas, com impactos nas atividades turísticas, na saúde, nas tradições e na história da população local (HOFSTAETTER et al., 2016). Os principais impactos das usinas eólicas são basicamente visuais, além de impactos sobre a fauna e flora, abrangendo desta forma, os meios: físico, biótico e socioeconômico (BARBOSA et al., 2013). Os empreendimentos eólicos não são diferentes dos demais, haja vista que a maioria causa algum impacto negativo, no entanto, quando comparados aos demais, os impactos ocasionados são menores e podem ser amenizados.

O reconhecimento da potencial geração de impactos ocasionados por um parque eólico, pode proporcionar o incentivo ou alerta para minimizar ou corrigir fatores que causam alterações indesejáveis, mas que podem ser evitadas, minimizadas ou corrigidas, possibilitando assim uma melhor gestão dos recursos naturais presentes na área de implantação do empreendimento. Do mesmo modo que valorar os impactos ambientais cometidos resulta em transformar os danos em valores econômicos, sendo um mecanismo para verificar se é compensatório a geração de energia eólica com base no valor econômico dos recursos ambientais do local do empreendimento. Fernandes (2015) afirma que o valor da degradação ambiental não está inserido nas atividades econômicas, que geralmente causam influencias ao meio ambiente. Nesse contexto, a presente pesquisa foi realizada objetivando -se estimar a valoração ambiental de um Parque eólico no Semiárido Paraibano.

\section{MATERIAIS E MÉTODOS}

A área de estudo está inserida em dois municípios, Santa Luzia e São José do Sabugi no estado da

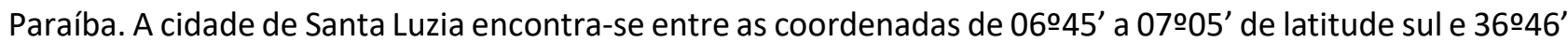
a 37002' de longitude oeste e altitude de 304m, com uma área de 455,702 km² (IBGE, 2010). O município de São José do Sabugí situa-se na região Centro-Norte do Estado da Paraíba, Mesorregião Borborema e Microrregião Seridó Ocidental Paraibano. Limita-se ao norte com Ouro Branco (RN) e Santana do Seridó (RN), leste com Santana do Seridó (RN) e Equador (RN), sul com Equador (RN) e Santa Luzia, e, oeste, com Santa Luzia e Ouro Branco (RN). Possui o município de São José de Sabugí área de 215,4 km² e insere-se na folha 
Jardim do Seridó (SB.24-Z-B-V) editada pelo MINTER/SUDENE no ano 1972. A sede municipal situa-se a uma altitude de 333 metros e possui coordenadas de 743.276EW e 9.250.450NS (CPRM, 2005).

O parque eólico denominado Lagoa 1, Figura 1, está localizado nas coordenadas Lat. 653'24" e Longe. $36^{\circ} 48^{\prime} 77^{\prime \prime}$, com uma produção de $69 \mathrm{Kw}$, sendo constatada uma área de 1,0172ha até 2017, calculada conforme os limites da área. A área de estudo em questão compõem um complexo constituído de três Parques Eólicos na Paraíba, (Canoas, Lagoa 1 e Lagoa 2), com um total de 45 aerogeradores e potência instalada total de $94500 \mathrm{Kw}$, cuja as obras estão sendo realizadas pela empresa Força Eólica do Brasil, com o apoio do Sistema Federação das Indústrias do Estado da Paraíba (FIEP) através do Departamento Regional do SENAI da Paraíba em Rede Nacional com o Departamento Regional do SENAI da Bahia (SÁ, 2017). O empreendimento de aproximadamente $\mathrm{R} \$ 98$ milhões.

A norma ABNT NBR 14653-6 2008 - Avaliação de Recursos Naturais, tem duas opções de valoração de áreas ambientais. O Método do Custo de Viagem (MCV) deriva os benefícios econômicos atribuídos pela população a um patrimônio natural a partir dos gastos efetivos dos visitantes para se deslocar até o local, o que inclui transporte, tempo de viagem, taxa de entrada, hospedagem, alimentação, entre outros gastos complementares (MAIA, 2008). O Método da Valoração Contingente ou Disposição a Pagar (DAP) identifica a disposição a pagar dos indivíduos pelo uso, preservação ou restauração de um recurso ambiental, ou a disposição a receber como compensação por sua perda ou pela queda da qualidade ambiental (ABNT, 2005).

Basicamente esses métodos indicam o quanto às pessoas estão dispostas a pagar para ter ou continuar tendo acesso a uma determinada área ou recurso natural, no entanto, é observado em ambos os métodos citados que trata-se de uma avaliação indireta, uma sondagem a respeito do gral de importância que uma população tem por uma área e não das condições em que se encontram os recursos presentes na área.

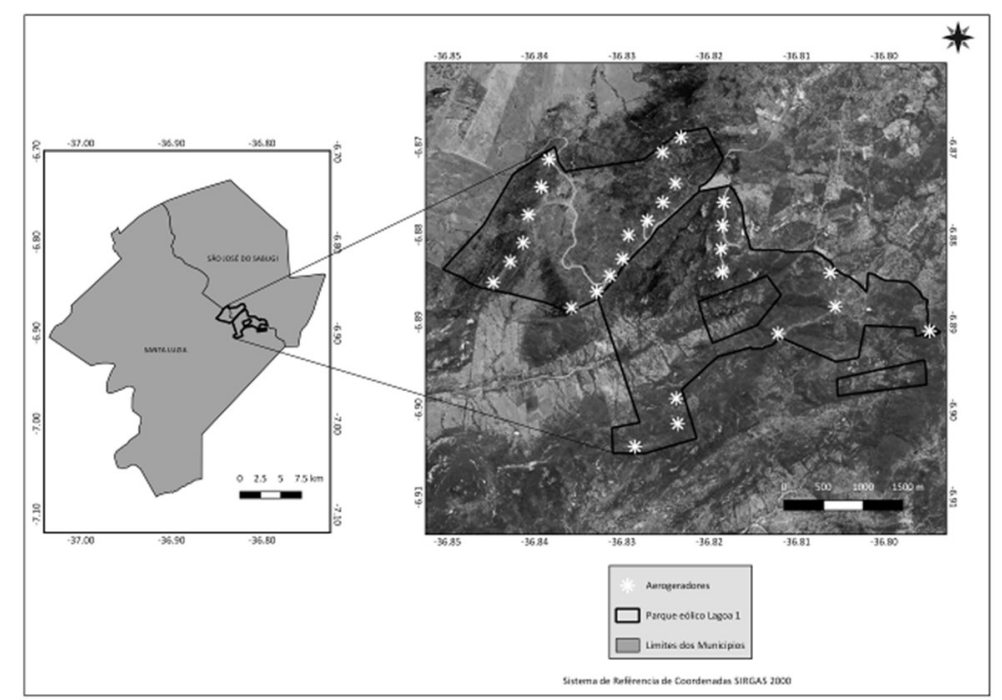

Figura 1: Localização do parque eólico denominado Lagoa 1.

A metodologia usada neste trabalho foi a Valoração de Área Ambiental, tendo em vista a simplicidade para sua compreensão e praticidade na aplicação, fundamentada na metodologia desenvolvida pelo Instituto Brasileiro de Avaliações e Perícias de Engenharia de São Paulo -IBAPE/SP, realizando uma análise de fatores ambientais e em seguida foi utilizada a equação 1, (IBAPE, 2015). 


$$
\mathrm{VA}=\mathrm{VPa} \times \mathrm{NIA}-\mathrm{PAS}, \quad \mathrm{Eq}(1)
$$

Onde:

$\mathrm{VA}=$ valor ambiental da área

VPa = valor paradigma da área, correspondente a quantia da terra nua (QTN), norma NBR 14653 (ABNT, 2004). NIA = número significativo da área ambiental. PAS = valor do passivo ambiental significativa que a área apresenta, ou seja 0,5\% do valor total do empreendimento. Esta característica representa os impactos ambientais negativos.

O número significativo da área ambiental (NIA) engloba alguns parâmetros como: Aspecto Ambiental 1 (A.1) - Significância da área no ciclo hidrológico e interceptação da precipitação atmosférica; Aspecto Ambiental 2 (A.2) - Significância da área no abrigo da fauna; Aspecto Ambiental 3 (A.3) - Relevância da área no ciclo do carbono; Aspecto Ambiental 4 (A.4) - Significância da área no conforto acústico dos frequentadores do local.

O número de importância para cada situação varia de 1 (muito baixa) a 5 (muito alta). Assim com a média do número de importância dos aspectos ambientais abordados, obtendo-se o valor total no número de importância da área (NIA), segundo a metodologia de IBAPE/SP (2015). Para o levantamento das informações necessárias em relação a área em estudo, realizou-se uma pesquisa bibliográfica e utilização de material audiovisual, como o vídeo passeio virtual no Parque Eólico Lagoa (I e II) e Canoas, bem com o uso de imagens trabalhadas e modeladas no Software QGIS 2.14.16 uma vez que não foi possível ter acesso direto a área para obtenção dos dados primários. Sendo possível o levantamento de alguns recursos naturais (topografia, solo, vegetação) para caracterizar a área, como se propõe a metodologia, para só então realizar a estimativa do valor ambiental do parque.

\section{RESULTADOS E DISCUSSÃO}

Para o aspecto ambiental 1 é considerado o tipo de solo e permeabilidade, declividade, pluviometria e cobertura vegetal (Tabela 1). Para o tipo de solo e permeabilidade o nível de importância considerada média (3), ou seja, sem afloramento de rochas ou afloramentos esparsos, com maior parte da área composta de solos argilosos e média permeabilidade (IBAPE, 2015).

Tabela 1: Aspecto ambiental 1 (A.1) - Significância da área no ciclo hidrológico e interceptação da precipitação atmosférica.

\begin{tabular}{|c|c|}
\hline \multicolumn{2}{|l|}{ ASPECTO AMBIENTAL 1} \\
\hline & Número de importância (ni) \\
\hline TIPO DE SOLO E PERMEABILIDADE & 3 \\
\hline DECLIVIDADE & 2 \\
\hline PLUVIOMETRIA & 1 \\
\hline COBERTURA VEGETAL & 3 \\
\hline$N F 1=(N I 1+N I 2+N I 3+N I 4) / 4$ & 2,25 \\
\hline
\end{tabular}

Fonte: Adaptado de IBAPE (2015).

A cobertura vegetal tem significância média (3), por haver cobertura vegetal natural com baixa densidade de indivíduos (IBAPE, 2015). Na Tabela 1, observa-se que ao fazer a média destes atributos, temse uma média de 2,25 , resultado referente principalmente as características da área em estudo, assim como em relação às atividades realizadas no local. 
A pluviometria tem importância muito baixa (1), decorrente da precipitação irregular e da má distribuída das chuvas na região, sendo uma das características fortes do semiárido. Tem-se uma área de pouca infiltração devido ao solo que é em grande parte, argiloso e de elevado escoamento superficial devido à topografia da região que é muito inclinada ou muito ondulada, segundo CPRM (2005). Conforme a Figura 2, o aspecto declividade foi considerado baixo (2) com topografia inclinada ou ondulada, com declividade variando entre $25 \%$ e $40 \%$, isso com relação à área ocupada pelo parque estudado. O perfil de declividade foi construído mediante indicação de um caminho traçado interligando os aerogeradores, através dele constata-se na Figura 2, que as torres foram instaladas sempre nos pontos de maior altura em relação à área ocupada, e a alteração do relevo ocorreu sempre de um ponto mais alto para um ponto mais baixo verificando valores negativos no eixo $\mathrm{Y}$ do gráfico, este que complementa o mapa de declividade da área.

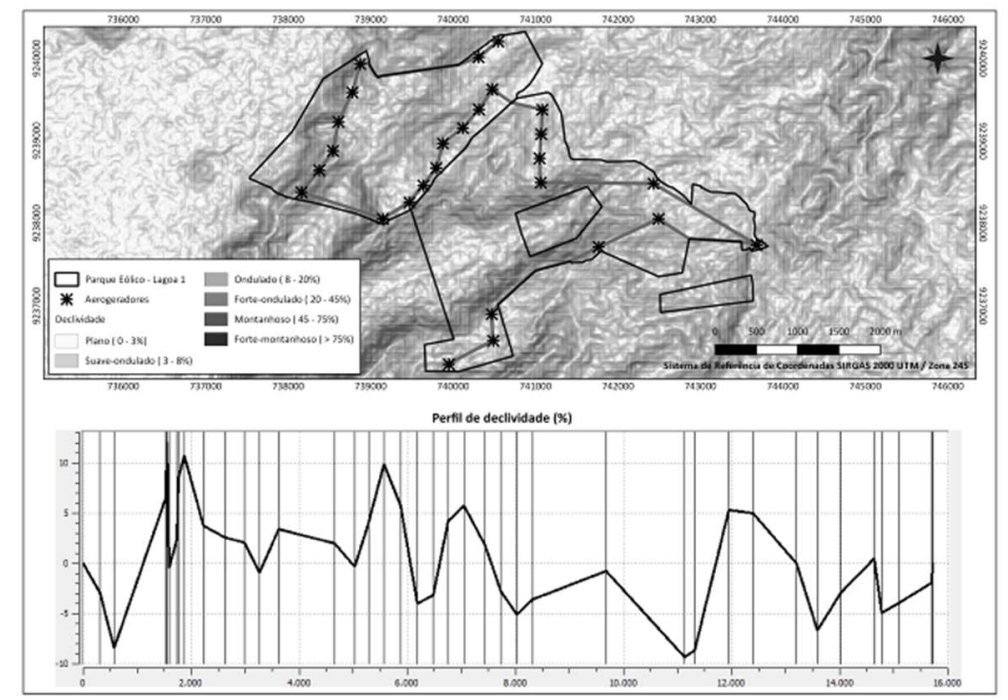

Figura 2: Declividade da Área do Parque Eólico Lagoa 1 e o Perfil de Declividade da região em estudo.

Mesmo com uma média anual de precipitação abaixo de 1000 mm, como afirmam Silva et al. (2011) e CPRM (2005), é perceptivo que a intensidade da chuva torrenciais na região semiárida é elevada apesar de ser de curta duração e que aceleram o processo de erosão em áreas expostas, desprovidas de vegetação. Barreto Filho (2018) expõe em seu trabalho que houve transformação significativa, a exemplo do evidente alargamento das estradas, na área de implantação do complexo eólico, principalmente no que se refere à vegetação e solo exposto. As evidências de formação de escoamento superficial e dos processos associados como a erosão, à transferência de solutos, de matéria orgânica e de nutrientes, são reflexos de que o manejo do solo não tem contribuído para a manutenção das funções do solo, especialmente daquelas associadas à regulação dos fluxos hidrológicos (DEUSCHLE, 2016).

Para implantação do Parque eólico o solo foi exposto, escavado e vias de acesso foram alargadas para chegar aos pontos de cada torre. As atividades de terraplanagem podem alterar o nível hidrostático do lençol freático, influenciando no fluxo de água subterrânea, visto que os cortes e aterros possivelmente serão submetidos a obras de engenharia para a estabilidade dos taludes e as vias compactadas para possibilitar a continuidade do tráfego de caminhões (BARBOSA et al., 2013), bem como escavação e concretagem para fixação das torres. 
Para a instalação da turbina, sua base é de concreto, assim o impacto no solo é pontual na área, sendo anteriormente realizados testes de compactação do solo para avaliar a situação de instalação de cada turbina, como não são utilizados combustíveis fósseis, não há contaminação por resíduos líquidos na operação e manutenção dos parques eólicos, reduzindo os riscos de contaminar os lençóis freáticos, segundo Souza et al. (2015).

O aspecto ambiental 2 é constituído por conectividade da área e antropização da área, averiguando a importância da área para abrigo da fauna. A antropização da área teve um índice considerado de alta tendendo para muito alta $(4,6)$ importância, sendo um dos aspectos responsáveis pela degradação ambiental e que afeta a permanência dos animais no local. Ao verificar a presença de visitantes, moradores do local, edificações no local e entorno, e a presença de ruas, avenidas e rodovias no entorno, com importância muito alta (5), quer dizer que quanto maior o nível de importância menor a presença de pessoas no local. Assim a modificação no ambiente está diretamente relacionada com a implantação do Parque eólico no local. Na Tabela 2, verifica-se que a conectividade da área é baixa (2), ou seja, área com conectividade a um ou mais fragmentos pequenos (IBAPE, 2015). O aspecto ambiental 2 em relação a importância da área para abrigo de animais, o nível de importância é médio $(3,3)$, com maior índice para fator antropização já que a presença de pessoas e moradias no local de estudo é muito baixa a ausente, tendo um elevado grau de importância ao meio ambiente.

A conectividade representa na paisagem o oposto da fragmentação, em linhas gerais, indica a magnitude da conexão entre os habitats e a respectiva capacidade de dispersão das espécies no espaço. O entendimento e a percepção sobre a atual conformação da paisagem, juntamente com as possibilidades de interpretação de um cenário passado e a previsão de uma situação futura no espaço, incrementam as possibilidades de ações de planejamento e gestão dos sistemas ambientais (RIBAS et al., 2016).

Tabela 2: Aspecto ambiental 2 (A2) - Significância da área no abrigo da fauna.

\begin{tabular}{|l|l|}
\hline ASPECTO AMBIENTAL 2 & Número de importância (NI) \\
\hline ÁREA COM CONECTIVIDADE A UM OU MAIS FRAGMENTOS- FAI2 & 2 \\
\hline ANTROPIZAÇÃO DA ÁREA - FAII2 & \\
\hline PRESENÇA DE VISITANTES NO LOCAL & 5 \\
\hline PRESENÇA DE MORADOR NO LOCAL & 5 \\
\hline PRESENÇA DE MORADOR NO ENTORNO & 3 \\
\hline PRESENÇA DE EDIFICAÇÕES NO LOCAL & 5 \\
\hline PRESENÇA DE EDIFICAÇÕES NO ENTORNO & 5 \\
\hline PRESENÇA DE RUAS, AVENIDAS E RODOVIAS O ENTORNO & 5 \\
\hline AI2 = (NII1 + NII2 + NII3 + NII4 + NII5 +NII6)/6 & 4,6 \\
\hline A2= (FAI2 + FAII2)/2 & 3,3 \\
\hline
\end{tabular}

Fonte: IBAPE (2015).

Os pássaros são a maior apreensão em relação à fauna em parque eólico, pois podem colidir com as torres de alta tensão e as turbinas eólicas dificultam a visualização. O comportamento dos pássaros deve ser analisado e a taxa de mortalidade varia de espécie e do ambiente (SOUZA et al., 2015). Da mesma forma os morcegos são afetados, segundo Arnett et al. (2013) nos EUA e Canada foram observados em ambientes de energia eólica redução da população dos morcegos, identificando elevada mortalidade nestes locais. 
Avaliando a magnitude da área no ciclo do carbono, observa-se as características da área em relação a vegetação especifica da área, modificando a metodologia para a área em estudo, com vegetação caatinga predominante na região. Sendo constatado vegetação arbustiva formada e consolidada, com arvores de porte pequeno e algumas em fase de desenvolvimento, com baixa importância (2), Tabela 3. Em relação ao estoque de $\mathrm{CO}_{2}$, como a vegetação é arbustiva formada e consolidada, o nível de importância é muito alta (5), dessa maneira com estas informações percebe-se que a vegetação é fundamental para o ciclo do carbono, principalmente as pertencentes do Bioma Caatinga. Na Tabela 3, verifica se que o número de importância de 3,5 como sendo de média a alta importância da área para o ciclo do carbono.

Tabela 3. Aspecto ambiental 3 (A3) - Relevância da característica da área no ciclo do carbono.

\begin{tabular}{|l|l|}
\hline ASPECTO AMBIENTAL 3 & Número de importância (NI) \\
\hline ÁREA PARA CAPTAÇÃO DE CO2 & 2 \\
\hline ÁREA PARA ESTOQUE DE CO2 & 5 \\
\hline A3 = (NI1 + NI2)/2 & 3,5 \\
\hline
\end{tabular}

Fonte: IBAPE (2015).

Moreira et al. (2006) relatam que a Caatinga é muito degradada pela exploração antrópica, principalmente pela pratica da agricultura, extração de madeira e a pecuária. A Caatinga é conhecida por sua floresta ter aspecto arbórea ou arbustiva, principalmente com árvores e arbustos baixos (PRADO, 2003). A planta através da fotossíntese capta $\mathrm{CO}_{2}$, tendo relação direta com a quantidade de biomassa que está em desenvolvimento, deste modo a retenção de $\mathrm{CO}_{2}$ é equivalente à biomassa produzida e preservação da vegetação da área (IBAPE, 2015). Silva (2012) estabelece o sequestro de carbono como a remoção do carbono da atmosfera e armazenado na biomassa vegetal. Avaliando o fluxo de $\mathrm{CO}_{2}$ no Bioma Caatinga, Cerqueira e Rocha (2007) observaram que $30 \%$ da caatinga estudada, cerca de $43,01 \%$ é classificada de ótimo fluxo de carbono e $10,91 \%$ é bom.

Sampaio et al. (2011) afirmam que locais cobertos com vegetação caatinga arbustiva nativa e arbórea têm um armazenamento de biomassa elevado quando comparado com locais com apenas vegetação herbácea ou plantações de culturas de curto período. Pesquisando sobre o sequestro de carbono em áreas de Caatinga, Morais et al. (2017), concluíram que em épocas de maior precipitação há maior armazenamento de carbono em áreas com espécies de caatinga preservada, afirmando que as transformações oriundas de ações antrópicas afetam o sequestro de carbono e influenciam diretamente todo processo fisiológico da vegetação caatinga.

Para verificar o conforto acústico da área do Parque eólico, a atenuação considerada é resultante da divergência esférica do som, uma atenuação de $6 \mathrm{~dB}$, desse modo com $20 \mathrm{~m}^{2}$ de um motor tem-se uma intensidade sonora de $60 \mathrm{~dB}$, a $40 \mathrm{~m}^{2}, 54 \mathrm{~dB}$ e a $80 \mathrm{~m}^{2}$ com $48 \mathrm{~dB}$ e assim por diante, duplicando a área de um ponto fixo tem-se o dobro da atenuação, conforme IBAPE (2015). Admitindo que para a fixação de uma torre utilize-se de 30 a $40 \mathrm{~m}^{2}$ ou 0,09 a 0,16ha, foi calculada a área (S) onde se atingiria 20 dB de atenuação, e dessa forma, utilizando o valor encontrado foi feita uma relação pela área total do parque, como pode ser verificado no cálculo a seguir o número referente à importância deste aspecto ambiental foi muito baixo, visto que o valor encontrado foi de 33,33\%., equação 2. 


$$
\frac{1,0172 \mathrm{ha}}{\mathrm{X}}=\frac{60 \mathrm{~dB}}{20 \mathrm{~dB}} \rightarrow \mathrm{X}=0,3391 \text { ha } \mathrm{S}=\frac{0,3391 \mathrm{ha} * 100 \%}{1,0172 \mathrm{ha}} \rightarrow S=33,33 \%
$$

O conforto acústico do local, Tabela 4 , teve índice de importância baixa, com nf = 2 para os frequentadores do local, já que a relação entre a área onde atinge $20 \mathrm{~dB}$ de atenuação e área total do terreno este entre $20 \%<S<35 \%$.

Tabela 4: Aspecto ambiental 4 (A4) - Significância da área no conforto acústico dos frequentadores do local.

\begin{tabular}{|l|l|}
\hline ASPECTO AMBIENTAL 4 & Número de importância (NI) \\
\hline CONFORTO ACUSTICO DOS FREQUENTADORES LOCAL & 2 \\
\hline A4= NI1 & 2 \\
\hline
\end{tabular}

Fonte: IBAPE (2015).

Tabassum-Abbasi et al. (2014) mencionam que o ruído proveniente da turbina é tido como uma distração, quando a pessoa é exposta num curto período, contudo ouvido diariamente este som ocasiona irritabilidade sendo um fator responsável por alguns problemas. Bakker et al. (2012) afirmam que estes problemas gerados na saúde humana devido a exposição contínua ao ruído da turbina podem estar ligados ao distúrbio do sono e psicológicos.

Para a determinação do valor da área ambiental, os impactos sobre o uso de terras são quantificados pela área ocupada, sendo que em geral ocupam 0,06 a 0,08 km²/MW (12-16MW/ $\left.\mathrm{km}^{2}\right)$, local que poderia ser utilizado para outra finalidade, como por exemplo agricultura. Em linhas gerais a instalação de parques eólicos, não altera significativamente o habitat natural, Souza et al. (2015).

Calculando o valor paradigma da terra nua da mesma área (VPa), em relação ao método de classificação, salienta-se que a classe de capacidade de uso dos solos é interligada a situação de acesso do imóvel. Isto é, dentre as condições de acessibilidade ao imóvel - ótima, muito boa, boa, regular, desfavorável ou ruim - aplica-se valores distintos, ou seja, em ordem decrescente as condições expostas anteriormente

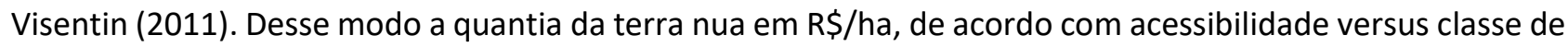
capacidade de uso para um local hipotético, aplicou a tabela de Lima (2005) como referência.

Quanto à acessibilidade e capacidade de uso do solo foi determinado o valor de R\$2.629,00 para cada hectare, uma vez que, apesar de não ser pavimentada, já existia uma BR na área de estudo e alterações impactantes aconteceram, como por exemplo, a abertura de novas estradas e o alargamento de estradas antigas desviando a rota tradicional Marx (2018). Quando verificado o número de importância da área (NIA) em estudo, após averiguar os quatros aspectos ambiental, obtêm-se de acordo com cálculo da equação 2 , valor maior que 2 .

$$
\begin{gathered}
\mathrm{NIA}=(\mathrm{nf} 1+\mathrm{nf} 2+\mathrm{nf} 3+\mathrm{nf} 4) / 4 \quad \mathrm{Eq}(2) \\
\mathrm{NIA}=(2,25+3,08+3,5+2) / 4 \\
\mathrm{NIA}=2,7075
\end{gathered}
$$

Conforme a equação 3, observa-se que a quantia da terra nua na área em análise é cerca de $\mathrm{R} \$$ 2674,22, ao multiplicar o valor obtido da terra em relação a acessibilidade e a capacidade de uso do solo naquela região.

$$
\mathrm{QTN}=\mathrm{R} \$ / \text { ha } 2.629,00 \times 1,0172 \mathrm{ha} \rightarrow \mathrm{QTN}(\mathrm{VPa})=\mathrm{R} \$ 2.674,2188 \quad \mathrm{Eq}(3)
$$


O valor do passivo ambiental significativo que a área apresenta (PAS) consistirá de $0,5 \%$ do valor total $(V t)$ investido, que foi previsto como sendo $R \$ 98.192 .000,00$ (noventa e oito milhões cento e noventa e dois mil reais) para implantação, equação 4. Desta forma foi determinado o valor de (PAS) igual a $R \$ 490.960,00$ (quatrocentos e noventa mil e novecentos e sessenta reais).

$$
\begin{gathered}
V t=R \$ 98.192 .000,00 \\
P A S=R \$ 98.192 .000,00 \times 0,5 \% \rightarrow R \$ 490.960,00 \quad E q(4)
\end{gathered}
$$

Na valoração de área ambiental é facultado valor a uma área, considerando aspectos ambientais, que são patrimônio ambiental que engloba os serviços ambientais que está área disponibiliza, bem como o passivo ambiental que possui, segundo IBAPE (2015). Aplicando-se a equação 5, proposta pela metodologia de valoração de área ambiental (VA), a estimativa de VA foi $R \$ 483.719,55$ (Quatrocentos e oitenta e três mil e setecentos e dezenove reais e cinquenta e cinco centavos). O valor foi negativo, referente ao valor ambiental da área, decorrentes dos impactos ambientais na área, já que o passivo ambiental é o valor atribuído aos danos ambientais significativos que caracterizam esse passivo IBAPE (2015). Desse modo, apesar da energia eólica ser considerada sustentável verifica-se que os danos ambientais são evidenciados e caso não levados em consideração podem ser ampliados a longo prazo.

$$
\begin{gathered}
V A=V P a \times N I A-P A S \quad E q(5) \\
V A=(R \$ 2.674,2188 \times 2,7075)-R \$ 490.960,00 \\
V A=-R \$ 483.719,55
\end{gathered}
$$

Caso o passivo ambiental não fosse levado em consideração a valoração da área seria estimada em $\mathrm{R} \$ \mathbf{7} .240,45$ (sete mil e duzentos e quarenta reais e quarenta e cinco centavos), observando um valor positivo, caso não houvesse impactos ambientais. A indicação do valor ambiental de uma área de implantação de um parque eólico é fundamental para aplicações financeiras, assim como a liberação de licenças ambientais e conservação das áreas não impactadas com o empreendimento. Quando é dado um valor monetário a uma área ambiental, fica evidenciado sua importância decorrente dos serviços ecossistêmicos proporcionados à população influenciando na percepção ambiental das pessoas e instituições (IBAPE, 2015).

\section{CONCLUSÕES}

A importância da área é quase média (3), com valor aproximado de 2,7. A estimativa da valoração ambiental foi negativa com valor de - $\mathrm{R} \$ 483.719,55$, decorrente da degradação ambiental na implantação dos aerogeradores, influenciando negativamente na avaliação da área após a implantação do parque. A área do parque eólico tem uma relevância ambiental em relação aos serviços ecossistêmicos prestados a sociedade, sendo necessário a conservação do local integrado ao funcionamento do empreendimento eólico na região.

\section{REFERÊNCIAS}


gerais, 2005.

ABNT. Associação Brasileira de Normas Técnicas. NBR 14653-3: Imóveis rurais Assets, 2004.

ALNASIR, Z.; KAZERANI, M.. An analytical literature review of stand-alone wind energy conversion systems from generator viewpoint. Renewable And Sustainable Energy Reviews, v.28, p.597-615, 2013. DOI: http://doi.org/10.1016/j.rser.2013.08.027

AQUILA, G.. Análise do impacto dos programas de incentivos para viabilizar economicamente o uso de fontes de energia renovável. Dissertação (Mestrado em Ciências em Engenharia de Produção).

Universidade Federal de Itajubá, Itajubá, 2015.

ARNETT, E. B.; BAERWALD, E. F.. Impacts of wind energy development on bats: implications for conservation. In: ADAMS, R. A.; PETERSON, S. C.. Bat evolution, ecology, and conservation. New York: Springer Science Press (in press), 2013.

AZEVEDO, J. P. M.; NASCIMENTO, R. S.; SCHRAM, I. B.. Energia eólica e Impactos Ambientais: um estudo de revisão. In: ENCONTRO LATINO AMERICANO DE INICIAÇÃO CIENTÍFICA, 20. ENCONTRO LATINO AMERICANO DE PÓS-GRADUAÇÃO, 26. ENCONTRO DE INICIAÇÃO À DOCÊNCIA, 6. Anais. Universidade do Vale do Paraíba, 2016.

BAKKER, R. H.; PEDERSEN, E.; VAN DEN BERG, G. P.; STEWART, R. E.; LOK, W.; BOUMA, J.. Impact of wind turbine sound on annoyance, self-reported sleep disturbance and psychological distress. Science of the Total Environment, v.425, p.42-51, 2012. DOI: https://doi.org/10.1016/j.scitotenv.2012.03.005

BARBOSA FILHO, W. P.; AZEVEDO, A. C. S.. Impactos ambientais em usinas eólicas. In: Agrener Gd Congresso sobre Geração distribuída e Energia no Meio Rural. São Paulo, 2015.

BEZERRA, F. D.; SANTOS, L. S.. Potencialidades da Energia Eólica no Nordeste. Caderno Setorial ETENE, v.2, n.5, p.2-19, 2017.

CERQUEIRA, D. B.; ROCHA, W. F.. Relação entre tipos de vegetação e fluxo de $\mathrm{CO}_{2}$ no Bioma Caatinga: Estudo de caso em Rio de Contas - Ba. In: SIMPÓSIO BRASILEIRO DE SENSORIAMENTO, 23. Anais. Florianópolis: INPE, p.2413-2419, 2007.

CPRM. Serviço Geológico do Brasil. Diagnóstico do município de São José do Sabugi. Programa de Desenvolvimento Enérgetico dos Estados e Municipios, 2005.

FERNANDES, K. D. S.. A valoração econômica e ambiental da lama depositada na costa da praia do Cassino: uma aplicação do método de valoração contingente. Monografia (Ciências Econômicas) Universidade Federal do Rio Grande, 2015.

HOFSTAETTER, M.; PESSOA, Z. S.. Energia eólica: um novo debate, entre defesas e contradições. In: CONGRESSO DE LA ASOCIACIÓN LATINO AMERICANA DE POBLACIÓN, 7. ENCONTRO NACIONAL DE ESTUDOS POPULACIONAIS, 20. Anais, 2016.

IBAPE. Instituto Brasileiro de Avaliações e Perícias de Engenharia de São Paulo. Valoração de área ambiental. Cartilha técnica. 2015.

IBGE. Instituto Brasileiro de Geografia e Estatística. Censo Demográfico. 2010.

LIMA, M. R. C.. Avaliações de propriedade rurais: manual básico. 2 ed. São Paulo: Universitária de Direito, 2005.

MAIA, A. G.; ROMEIRO, A. R.. Validade e confiabilidade do método de custo de viagem: um estudo aplicado ao parque nacional da serra geral. Economia Aplicada, São Paulo, v.12, n.1, p.103-123, 2008. DOI: http://dx.doi.org/10.1590/S141380502008000100005

MARX, E.. Expedição do CERSA avalia impactos de parques eólicos no Vale do Sabugi (PB). Comitê de Energia Renovável do Semiárido (CERSA), 2017.

MORAIS, Y. C. B.; ARAUJO, M. S. B.; MOURA, M. S. B.; GALVÍNCIO, J. D.; MIRANDA, R. Q.. Análise do sequestro de carbono em áreas de Caatinga do Semiárido Pernambucano. Revista Brasileira de Meteorologia, v.32, n.4, p.585-599, 2017. DOI: http://dx.doi.org/10.1590/0102-7786324007

MOREIRA, J. N.; LIRA, M. A.; SANTOS, M. V. F.; FERREIRA, M. A.; ARAUJO, G. G. L.. Caracterização da vegetação de Caatinga e da dieta de novilhos no Sertão de Pernambuco. Pesquisa agropecuária brasileira, Brasília, v.41, n.11, p.1643-1651, 2006.

NUNES, G. A.; MANHÃES, A. A. Energia eólica no Brasil: uma alternativa inteligente frente às demandas elétricas atuais. Revista de divulgação do Projeto Universidade Petrobras e IF Fluminense, v.1, n.1, p.163-167, 2010.

PRADO, D. E.. As Caatingas da América do Sul. In: LEAL, R. I.;TABARELLI, M.; SILVA, J. M. C.. Ecologia e conservação da Caatinga. Recife: UFPE, 2003.

SÁ, S.. Energia limpa: Paraíba terá três Parques Eólicos até 2017. Unidade de Inovação, Tecnologia e Projetos (UNITEC/SENAI) e Núcleo de Energia e Meio Ambiente, 2017.

SAMPAIO, E. V. S. B.; COSTA, T. L.. Estoques e fluxos de carbono no Semiárido Nordestino: estimativas 
preliminares. Revista Brasileira de Geografia Física,

Pernambuco, v.4, n.6, p.1275-1291, 2011.

SILVA, B. B.. Estimativa de sequestro de carbono por sensoriamento remoto. In: GALVÍNCIO, J. D..

Mudanças climáticas e modelo ambientais:

caracterização e aplicações. Recife: UFPE, 2012. p.5170.

SILVA, V. P. R.; PEREIRA, E. R. R.; AZEVEDO, P. V.; SOUSA, F. D. S.; SOUSA, I. F.. Análise da pluviometria e dias chuvosos na região Nordeste do Brasil. Revista Brasileira Engenharia Agrícola e Ambiental, v.15, n.1, p. 131-138, 2011. DOI: http://doi.org/10.1590/S141543662011000200004

SOUZA, L. L.; CUNHA, R. B.; SILVA, A. V.; SANTOS, M. H. $P$.. Análise do impacto ambiental causado pela geração de energia eólica. Engenharia, v.1, n.1, p.79-82, 2015.
TABASSUM-ABBASI, M.; PREMALATHA, T. A.. Wind energy: Increasing deployment, rising environmental concerns. Renewable and Sustainable Energy Reviews, v.31, n.1, p.270-288, 2014. DOI: https://doi.org/10.1016/i.rser.2013.11.019

TRALDI, M.. Novos usos do território no semiárido nordestino: implantação de parques eólicos e valorização seletiva nos municípios de Caetité (BA) e João Câmara (RN). Dissertação (Mestrado em Geografia) - Universidade Estadual de Campinas, São Paulo, 2014.

VISENTIN, J. B.. Avaliação de propriedades rurais impactadas por empreendimentos energéticos. Monografia (Agronomia) - Universidade Federal de Santa Catarina, 2011.

A CBPC - Companhia Brasileira de Produção Científica (CNPJ: 11.221.422/0001-03) detém os direitos materiais desta publicação. Os direitos referem-se à publicação do trabalho em qualquer parte do mundo, incluindo os direitos às renovações, expansões e disseminações da contribuição, bem como outros direitos subsidiários. Todos os trabalhos publicados eletronicamente poderão posteriormente ser publicados em coletâneas impressas sob coordenação da Sustenere Publishing, da Companhia Brasileira de Produção Científica e seus parceiros autorizados. Os (as) autores (as) preservam os direitos autorais, mas não têm permissão para a publicação da contribuição em outro meio, impresso ou digital, em português ou em tradução. 